\title{
MATCH OF SOLUBILITY PARAMETERS BETWEEN OIL AND SURFACTANTS AS A RATIONAL APPROACH FOR THE FORMULATION OF MICROEMULSION WITH A HIGH DISPERSED VOLUME OF COPAIBA OIL AND LOW SURFACTANT CONTENT
}

\author{
Xavier-Junior, F.H. ${ }^{1,2}$, Huang, N. ${ }^{1}$, Vachon, J. J. ${ }^{1}$, Rehder, V. L. G. ${ }^{3}$, Egito, E.S.T. ${ }^{2}$, \\ Vauthier, C. ${ }^{1 *}$ \\ ${ }^{1}$ Université Paris Sud, Institut Galien Paris-Sud - UMR CNRS 8612 - Faculté de Pharmacie, \\ 92296 Chatenay-Malabry Cedex - France. \\ ${ }^{2}$ Universidade Federal do Rio Grande do Norte, Centro de Ciências da Saúde, Departamento de \\ Farmácia, Laboratório de Sistemas Dispersos (LaSiD). Av. Gal. Gustavo Cordeiro de Farias, \\ S/N, Petrópolis, 59010-180, Natal-RN-Brazil. \\ ${ }^{3}$ Universidade Estadual de Campinas (UNICAMP) - Centro Pluridisciplinar de Pesquisas \\ Químicas, Biológicas e Agrícolas. Rua Alexandre Cazelatto, 999, Vila Betel, Paulínia - SP.
}

Published in: Pharm Res 2016; 33(12):3031-3043. doi: 10.1007/s11095-016-2025-y.

\author{
*Corresponding author: Christine Vauthier \\ Université Paris Sud, Institut Galien Paris-Sud - UMR CNRS 8612 - Faculté de Pharmacie, 92296 \\ Chatenay-Malabry Cedex - France. \\ christine.vauthier@u-psud.fr
}

\begin{abstract}
Purpose: Aim was to formulate oil-in-water (O/W) microemulsion with a high-volume ratio of complex natural oil, i.e., copaiba oil and low surfactant content. The strategy of formulation was based on (i) the selection of surfactants based on predictive calculations of chemical compatibility between their hydrophobic moiety and oil components and (ii) matching the HLB of the surfactants with the required HLB of the oil. Method: Solubility parameters of the hydrophobic moiety of the surfactants and of the main components found in the oil were calculated and compared. In turn, required HLB of oils were calculated. Selection of surfactants was achieved matching their solubility parameters with those of oil components. Blends of surfactants were prepared with HLB matching the required HLB of the oils. Oil/water mixtures (15/85 and 25/75) were the titrated with surfactant blends until a microemulsion was formed. Results: Two surfactant blends were identified from the predictive calculation approach. Microemulsions containing up to $19.6 \%$ and $13.7 \%$ of selected surfactant blends were obtained. Conclusion: O/W microemulsions with a high-volume fraction of complex natural oil and a reasonable surfactant concentration were formulated. These microemulsions can be proposed as delivery systems for the oral administration of poorly soluble drugs.
\end{abstract}

Keywords: Microemulsion, copaiba oil, solubility parameters, HLB, oil-in-water 


\section{LIST of ABBREVIATIONS}

$\begin{array}{ll}E_{h i} & \text { Hydrogen bonding energy of the partial group } \\ \mathrm{F}_{\mathrm{di}} & \text { Dispersion energy of the partial group } \\ \mathrm{F}_{\mathrm{pi}} & \text { Polar energy of the partial group } \\ \mathrm{GC}-\mathrm{FID} & \text { Gas chromatography - flame ionization detector } \\ \mathrm{GC}-\mathrm{MS} & \text { Gas chromatography-mass spectrometry } \\ \mathrm{HLB} & \text { Hydrophilic-lipophilic balance } \\ \mathrm{HLB} \mathrm{B}_{0} & \text { Required hydrophilic-lipophilic balance } \\ \mathrm{HLB}_{\text {oessential oil }} & \text { Required hydrophilic-lipophilic balance of copaiba essential oil } \\ \mathrm{HLB}_{\text {ooil }} & \text { Required hydrophilic-lipophilic balance of an oil } \\ \mathrm{HLB}_{0 \text { resin }} & \text { Required hydrophilic-lipophilic balance of copaiba resin oil } \\ \mathrm{K} & \text { Constant applied to O/W emulsion } \\ \mathrm{O} / \mathrm{W} & \text { Oil-in-water } \\ \mathrm{Pdl} & \text { Polydispersity index } \\ \mathrm{V} & \text { Molar volume } \\ \mathrm{W} & \text { Weight fractions of the surfactants/ compound } \\ \delta_{\mathrm{d}} & \text { Dispersive partial solubility parameters } \\ \delta_{\mathrm{h}} & \text { Hydrogen bonding partial solubility parameters } \\ \delta_{\mathrm{p}} & \text { Polar partial solubility parameters } \\ \delta_{\mathrm{t}} & \text { Total solubility parameter }\end{array}$




\section{INTRODUCTION}

Microemulsions are colloidal system of potential interest in pharmacy to improve bioavailability of poorly soluble drugs delivered by the oral route (1-4). They occurred as isotropic, thermodynamically stable, and single-phase liquid systems formed by mixing oil, water, and surfactants (5-7). Natural oils used in folk medicine have found growing interest over the past decades because of their numerous therapeutic activities. For instance, copaiba oil extracted from Copaifera langsdorffii contains phytochemicals including diterpenes and sesquiterpenes hydrocarbons which have been attributed anti-inflammatory, antitumoral, antimicrobial (antitetanus, antiblenorrhagea, antileishmania) and expectorant activities (8-10). It is assumed that the lipophilic nature of copaiba oil components hampers their full efficacy by the oral route because being non soluble in biological fluids, their absorption remains low hence their bioavailability. Microemulsions appear as suitable formulations to enhance bioavailability of lipophilic compounds with similar physicochemical profiles improving their therapeutic effects $(11,12)$.

To develop microemulsion systems, infinity of different ratios, components and methods can be combined. In general, formulation of microemulsions remains quite empirical and mainly based on the realization of phase diagrams (13-15). Amount of surfactants needed to formulate microemulsions is generally quite high while the fraction of the composition represented by the dispersed oil remains low as illustrated in Figure 1A (13-36). Thus, the oil/surfactant ratio of microemulsions described in the literature are generally below 1 due to a higher amount of surfactant required to stabilize the oil droplets of the microemulsion (Figure 1B). The large amount of surfactant hampers the development of microemulsions because of it is the root of toxicity $(37,38)$. Formulating microemulsions with a low amount of surfactant and higher content in dispersed oil is challenging but it is needed to reduce toxicity of this kind of such delivery system and to increase the amount of drug to be delivered.

The aim of the present work was to formulate O/W microemulsions with copaiba resin and essential oil as dispersed phase realizing the challenge to prepare microemulsions with a high content of copaiba oil (above 15\%) in the dispersed phase while the oil to surfactant ratio will be above 1 . 

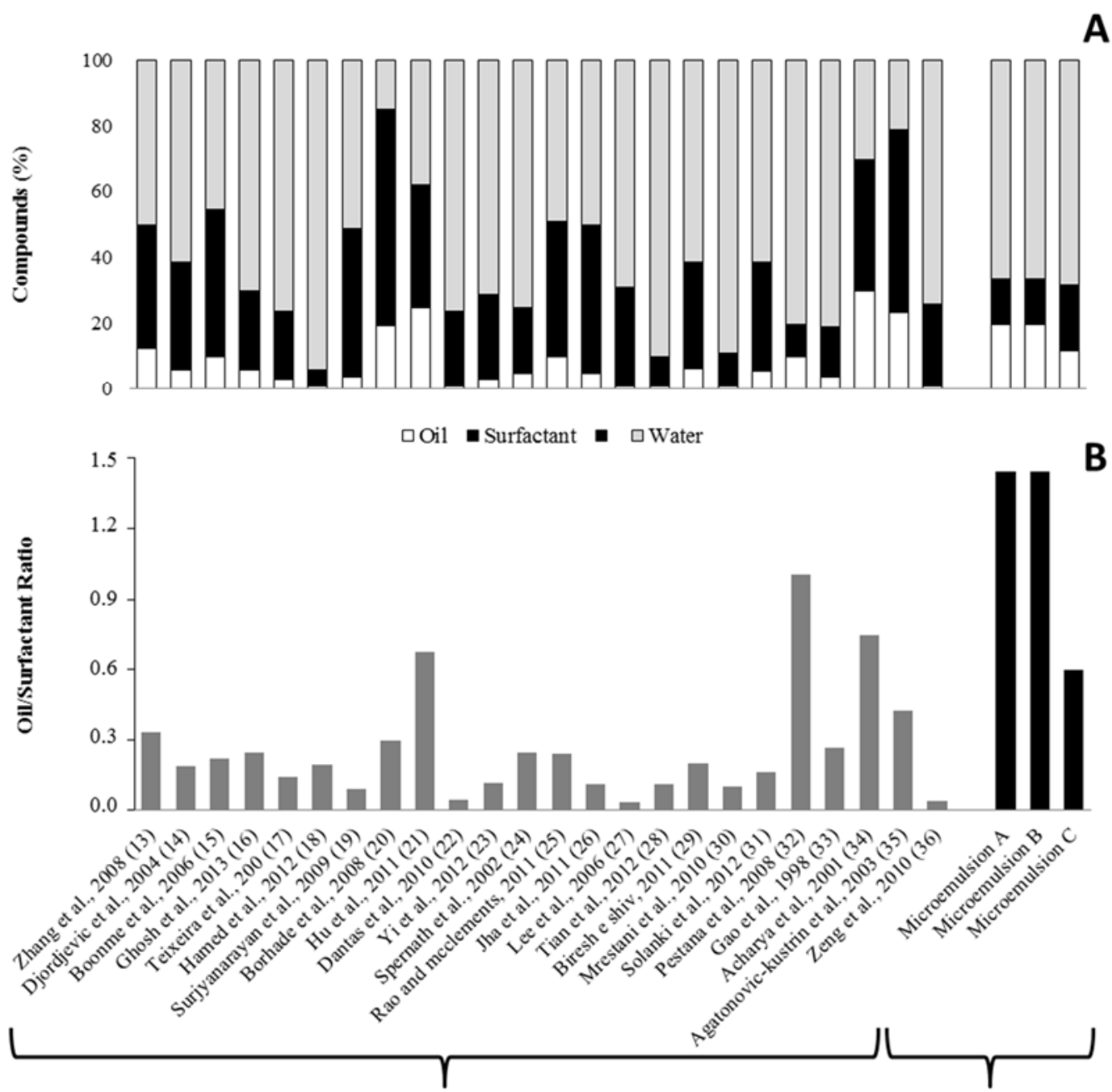

Microemulsions from the literature

This work

Figure 1 Comparison among the microemulsion containing copaiba oil obtained by solubility parameter approach with other different microemulsion from the literature. A-represent the ratio of the aqueous phase/surfactant+cosurfactant/Oil phase composing the microemulsion, where white, black and gray colors represent the oil phase, the surfactant (and/or cosurfactant) and aqueous phase contributions (\%) to microemulsion composition, respectively. $B$ - show the ratio between the oil and surfactant (and/or cosurfactant) compounds, gray columns showed the data from the literature and the dark column denoted microemulsion $A$ and $B$ composed of copaiba essential oil produced in the present work using Pluronic ${ }^{\circ}$ F-68: Brij ${ }^{\circ}$ 010 at 1.1:98.9 (w/w) ratio and Tween ${ }^{\circ} 20:$ Brij $^{\circ} 010$ at 4.2:95.8 (w/w) ratio, respectively and microemulsion C composed of copaiba resin oil produced with Tween ${ }^{\circ} 20$ : Brij ${ }^{\circ}$ O10 at 13.4: $86.6_{(w / w)}$ ratio.

To achieve this aim, it was suggested to use a rational approach selecting surfactants based on the miscibility and chemical match of their lipophilic moiety with major components of the copaiba oil. Models predicting miscibility and compatibility of a mixture system based on the evaluation of cohesive energy density of substances are important in drug formulations (3941). They were also found essential to optimize emulsion formulations (42). One approach is based on the comparison of Hansen solubility parameters and on the calculation of the 
required hydrophilic-lipophilic balance $(\mathrm{HLB})$ of the oil $\left(\mathrm{HLB}_{0 \mathrm{oil}}\right)$ according to Beerbower and Hill $(43,44)$. In the past, the application of this approach to the formulation of inverse microemulsions (water-in-oil microemulsions) was a success to obtain microemulsions with a low concentration of surfactant (down to $5 \%$ ) while the volume fraction of the dispersed aqueous phase was above $40 \%$ (45). Such a method was not yet applied to the formulation of $\mathrm{O} / \mathrm{W}$ microemulsion. It was also never applied considering the use of natural oil that is a complex mixture of compounds. It was assumed that this approach could be used (i) to identify appropriate surfactants based on the optimization of the chemical compatibility of the chemical species that will be attended to mixed and (ii) to optimize the HLB of the surfactant to obtain $\mathrm{O} / \mathrm{W}$ microemulsions with a high-volume fraction of dispersed oil while the amount of surfactant will be reduced.

\section{MATERIALS AND METHODS}

\subsection{Materials}

Copaiba oil was purchased from Flores \& Ervas (Piracicaba, SP, Brazil). Poly(oxyethylene) (10) oleyl ether (Brij ${ }^{\bullet}$ O10), Polyethylene glycol sorbitan monolaurate (Tween ${ }^{\circ} 20$ ), Poly(oxyethylene)-poly(oxypropylene) block copolymer (Pluronic ${ }^{\circ} \mathrm{F}-68$ ), and $\beta$-caryophyllene were provided by Sigma-Aldrich (Saint-Quentin Fallavier, France). Ultrapure water was obtained from a Millipore purification system (Milli-Q plus, Millipore, St Quentin en Yvelines, France). Ethyl acetate and Ethanol were purchased from Fisher Scientific (Illkirch, France). All chemicals reagent grade were used as received.

\subsection{Copaiba essential oil extraction}

Copaiba essential oil was obtained from $400 \mathrm{~mL}$ of copaiba resin oil by hydro distillation using a Clevenger-type apparatus for $3 \mathrm{~h}$. The extract was dried with sodium sulphate, filtered and stored at $-20^{\circ} \mathrm{C}$. Aliquots $(10-20 \mathrm{mg})$ of the oil were dissolved in ethyl acetate $(1 \mathrm{~mL})$ and analyzed by a validated gas chromatography method (46).

\subsection{Gas chromatography - Flame Ionization Detector and mass spectrometry analyses}

Analysis of the composition of copaiba oil was performed by gas chromatography-flame ionization detector and mass spectrometry as described by Xavier-Junior et al. (46). Briefly, main components of copaiba essential oil-loaded microemulsion and copaiba essential oil 
alone were determined. The apparatus used was a PR2100 gas chromatography (Alpha MOS, Toulouse, France) interfaced with a Flame Ionization Detector (GC-FID) and Hewlett-Packard 6890 gas chromatography (Agilent Technologies, Santa Clara, CA, EUA) with HP-5975 mass selective detector (GC-MS). A fused silica capillary column ( $25 \mathrm{~m} \times 0.32 \mathrm{~mm}$ i.d., $0.5 \mu \mathrm{m})$ film thickness coated with cross-linked 5\% phenyl polysilphenylene-siloxane (SGE Analytical Science Pty Ltd, Victoria, Australia) was used as the separation capillary. The injector and detector temperatures were set at 250 and $300^{\circ} \mathrm{C}$, respectively. The start of column heating was set at $90{ }^{\circ} \mathrm{C}$, with heating ramp of $2^{\circ} \mathrm{C} \cdot \mathrm{min}^{-1}$ to $150{ }^{\circ} \mathrm{C}$, then isothermally heating $20^{\circ} \mathrm{C} \mathrm{min}-1$ to 300 ${ }^{\circ} \mathrm{C}$. Helium was used as carrier gas at $1 \mathrm{~mL} \cdot \mathrm{min}^{-1}$. The GC-MS electron ionization system was set at $70 \mathrm{eV}$. The volume injected for all samples was $1 \mu \mathrm{L}$. The oil components were identified by comparing their mass fragmentation with data from the electronic library from the Wiley 6 , aro_cnrs, F\&F_Lib_Argeville, MainLib and Aromes libraries and published data elsewhere. The $\beta$-caryophyllene was selected as the standard for the studies of copaiba oil quantification.

\subsection{Solubility Parameters: method of calculation}

The group contribution method was used to calculate solubility parameters of the main compounds composing copaiba oil and of the hydrophobic moiety of a series of surfactants knowing their molecular structure. Surfactants selected to perform the calculations can be incorporated in pharmaceutical formulations designed to be administered by the oral route. Calculation of solubility parameters were performed according to the Hansen approach using equations 1 and 2.

$$
\begin{gathered}
\delta_{\mathrm{d}=} \frac{\sum \mathrm{F}_{\mathrm{di}}}{\mathrm{V}} \delta_{\mathrm{p}=} \frac{\sqrt{\sum \mathrm{F}_{\mathrm{pi}}^{2}}}{\mathrm{~V}} \delta_{\mathrm{h}=\sqrt{\frac{\sum \mathrm{E}_{\mathrm{hi}}}{\mathrm{V}}}(\mathrm{Eq} 1)} \\
\delta_{\mathrm{t}}^{2}=\delta_{\mathrm{d}}^{2}+\delta_{\mathrm{p}}^{2}+\delta_{\mathrm{h}}^{2}(\mathrm{Eq} 2)
\end{gathered}
$$

Where $\delta_{t}, \delta_{d}, \delta_{p}$, and $\delta_{h}$ were the total solubility parameter and dispersive, polar and hydrogen bonding partial solubility parameters of components, respectively. $F_{d i}, F_{p i}$ and $E_{h i}$ were the molar attraction constants due to dispersion, polar and hydrogen bonding energy of the partial group, respectively, and $\mathrm{V}$ is the group contribution to molar volume. The values of the group contributions were taken from tables of the literature (Table S1) (47). Solubility parameters of the lipophilic moiety of surfactants were calculated with the same method. 


\subsection{Calculation of the HLB of surfactants and of the required $\mathrm{HLB}_{0}$ of copaiba oil.}

HLB of non-ionic surfactants were calculated from the molecular weight ratio between their hydrophilic moieties and entire molecule (equation 3). The determination of the HLB of surfactant blends and $\mathrm{HLB}_{0}$ total of the copaiba oils were calculated according the equation 4 $(48,49)$.

$$
\begin{gathered}
\mathrm{HLB}_{\text {value }}=20 . \frac{\text { Mw hydrophilic potion }}{\text { Mw entire molecule }}(\mathrm{Eq} 3) \\
\mathrm{HLB}_{\text {blend }}=\frac{\mathrm{W}_{\mathrm{A}} \mathrm{HLB}_{\mathrm{A}}+\mathrm{W}_{\mathrm{B}} \mathrm{HLB}_{\mathrm{B}}}{\mathrm{W}_{\mathrm{A}}+\mathrm{W}_{\mathrm{B}}}(\mathrm{Eq} 4)
\end{gathered}
$$

Where $W_{A}$ and $W_{B}$ were the weight fraction of the first and second surfactants/compound used, respectively, the $\mathrm{HLB}_{A}$ and $H \mathrm{HB}_{B}$ are the assigned $\mathrm{HLB}$ values for surfactants/compound $A$ and $B$, respectively.

The required Hydrophilic-Lipophilic Balance $\left(\mathrm{HLB}_{0}\right)$ of copaiba oil main compounds were determined using the previously calculated solubility parameters in $\mathrm{cal}^{1 / 2} \mathrm{~cm}^{-3 / 2}\left(1 \mathrm{cal}^{1 / 2} \mathrm{~cm}^{-3 / 2}=\right.$ $2.045 \mathrm{MJ}^{1 / 2} \mathrm{~m}^{-3 / 2}$ ) (equation 5):

$$
\mathrm{HLB}_{0}=\frac{20}{1+\mathrm{K} /\left[\delta_{\mathrm{d}}^{2}+0.25 \delta_{\mathrm{p}}^{2}+0.25 \delta_{\mathrm{h}}^{2}\right]_{\mathrm{L}}}(\mathrm{Eq} 5)
$$

The value of $\mathrm{K}$ for an $\mathrm{O} / \mathrm{W}$ emulsion is $43(42)$. The $\mathrm{HLB}_{0}$ was calculated from each main component of copaiba oil extracts considered in the work. A global value of the HLB $B_{0}$ was then calculated for the oil taking into account the composition of the oil in the different components based on equation 6 assuming an additive law as that used to calculate HLB of blends of surfactants

$$
\mathrm{HLB}_{0 \text { oil }}=\frac{\mathrm{W}_{\mathrm{A}} \mathrm{HLB}_{0 \mathrm{~A}}+\mathrm{W}_{\mathrm{B}} \mathrm{HLB}_{0 \mathrm{~B}}+\mathrm{W}_{\mathrm{C}} \mathrm{HLB}_{0 \mathrm{C}}+\cdots}{\mathrm{W}_{\mathrm{A}}+\mathrm{W}_{\mathrm{B}}+\mathrm{W}_{\mathrm{C}}+\cdots}(\mathrm{Eq} 6)
$$

Where $W_{A}, W_{B}$ and $W_{C}$ were the weight fractions of the different compounds composing the oil and the $H \angle B_{O A}, H L B_{0 B}$ and $H L B_{0 C}$ were the assigned required $H L B$ values for components $A, B$ and $\mathrm{C}$.... respectively. 


\subsection{Preparation of the microemulsion}

The formulation of O/W microemulsions was explored considering two copaiba oil extracts, the copaiba resin oil and the copaiba essential oil. Copaiba oil extracts and Milli-Q water were weighed at 25:75 and 15:85 $(\mathrm{w} / \mathrm{w})$ ratios of $1 \mathrm{~g}$ per batch. Thereafter, surfactant either pure or in blends Tween ${ }^{\circledR}$ 20:Brij $010(4.2: 95.8(w / w))$ or Pluronic ${ }^{\circledR}$ F-68: Brij ${ }^{\circledR} \mathrm{O} 10(1.1: 98.9(w / w))$ which compositions were defined from the previous calculations were sequentially added to the copaiba oil extract/Milli- ${ }^{\circ}$ water mixtures. After each addition of $50 \mathrm{mg}$ of surfactant, the system was sonicated (Misonix XL 2020 sonicator, Farmingdale, NY, U.S.A) at $40 \%$ amplitude for 60 seconds followed by an ultrasonic bath for 10 minutes at $25^{\circ} \mathrm{C}$ (Elma Elmasonic $\mathrm{S} 10 \mathrm{H}$, Elma Hans Schmidbauer GmbH \& Co. KG, Singen, Germany) and the turbidity was monitored out on the UV-VIS-Fibre Optics Spectrometer AVS-S2000 with DH-2000 deuterium Halogen light source and AvaSoft software package (Avantes, Apeldoorn, Netherlands). The addition of surfactant was pursued until a clear and transparent system was obtained.

\subsection{Characterization of the microemulsion}

\subsubsection{Transmittance measurements}

Transmittance of the samples were evaluated at $37^{\circ} \mathrm{C}$ at the wavelength $650 \mathrm{~nm}$ using a plugin spectrometer PC 2000 equipped with an optical fibers (100 $\mu \mathrm{m}$ core) carying the incident light from the light source (HL-2000-Cal) and a second optical fiber (200 $\mu \mathrm{m}$ core) carying the transmitted light to the analyzer (Ocean Optics Europe, Lannion, France).

\subsubsection{Light microscopy}

Microemulsions were observed by light microscopy using a contrast phase mode and under polarized light to determine optical isotropy using a Nikon E600 Eclipse direct microscope (Champigny/Marne, France). The microscope was equipped with a long focus objective (LWD $40 \times 0.55 ; 0-2 \mathrm{~mm}$ ) and a Nikon Coolpix 950 camera was used to record the images with a resolution of $1600 \times 1200$ pixels.

\subsection{3. $\mathrm{pH}$ analysis}

The $\mathrm{pH}$ values of the microemulsions were measured with a pH meter (model $\mathrm{HI} 8417$, Hanna Instruments Inc., Woonsocket, USA), at $20 \pm 2{ }^{\circ} \mathrm{C}$. 


\subsubsection{Size measurement}

The hydrodynamic mean diameter and the size distribution of the microemulsion were determined by dynamic light scattering, using a He-Ne laser (wavelength of $633 \mathrm{~nm}$ ) and a detector angle of $90^{\circ}$ in a Malvern Zetasizer (NANO ZS90, Malvern Instruments Limited, UK). For size distribution measurements, a dispersion of diluted microemulsion in Milli- $Q^{\circ}$ water (1:100) was analyzed at $25{ }^{\circ} \mathrm{C}$ in a polystyrene cell. Cumulates analysis provides the characterization of a sample through the mean value (z-average) for the droplet size and polydispersity index (Pdl).

\subsubsection{Determination of the zeta potential}

Zeta potential of the microemulsion was deduced from the determination of the electrophoretic mobility by Laser Doppler Electrophoresis (Zetasizer Nano ZS90 (Malvern Instruments Ltd, Orsay, France). Microemulsion were diluted (1:50) with $\mathrm{NaCl}$ at $1 \mathrm{mmol} / \mathrm{L}$. Values are presented as mean of measurements performed on three replicate samples.

\subsubsection{Rheological behavior}

Rheological properties of the microemulsion were determined using a rotational rheometer AR-G2 (TA instruments, New Castle, USA). Measurements were performed with an aluminum cone/plate geometry with a diameter of $40 \mathrm{~mm}$, an angle of $1^{\circ}$ and a truncation gap of $28 \mu \mathrm{m}$. Samples were maintained at $37 \pm 0.1{ }^{\circ} \mathrm{C}$ using a Peltier plate. Analyses were carried out by applying a 5 -min shear rate sweep from $10^{-1}$ to $10^{3} \mathrm{~s}^{-1}$, after 3 minutes of equilibrium time. Measurements were performed in triplicate.

\subsection{Determination of copaiba oil content in the microemulsion}

The composition of copaiba oil in the microemulsion was determined as follows. Briefly, $1 \mathrm{~mL}$ of the microemulsion prepared with copaiba essential oil was centrifuged at speed of $8500 \mathrm{xg}$ for 15 min (Eppendorf centrifuge 5418, Rotor FA-45-18-11, Hamburg, Germany) to remove eventual residues of titanium that may have been released from the ultrasound tip. The supernatant was used to analyze the composition of the oil composing the dispersed phase of the microemulsion. Thus, the oil contained in $20 \mu \mathrm{L}$ of the supernatant was extracted with 1 $\mathrm{mL}$ of ethyl acetate under sonication using an ultrasonic bath (Elma Elmasonic S10H, Elma Hans Schmidbauer GmbH \& Co. KG, Singen, Germany) for 15 minutes. The solution was filtered with a $0.1 \mu \mathrm{m}$ teflon filter (Merck Millipore, Billerica, MA, EUA). GC-FID method was used to measure the content of copaiba oil, in particular, $\beta$-Caryophyllene according the previous validation studies as described above and to analyze the composition of the oil (46). 


\subsection{Statistical analysis}

All the experiments were conducted in triplicates. Means of two groups were compared using non-paired Student's t-tests. All values were expressed as their mean \pm S.D. When comparing multiple groups, one way analysis of variance (ANOVA) was applied with the Tukey multiple comparison procedure. The statistical data were considered significant at $p<0.05$.

\section{RESULTS AND DISCUSSION}

\subsection{Copaiba oil characterization}

Figure 2 shows chromatograms given from the analysis of the two copaiba oil extracts considered in the present work that included the copaiba resin and the essential oil obtained from Copaifera langsdorffii. In agreement with previous work, the assays allowed to identify 20 components in the copaiba resin oil among which 10 were sesquiterpenes and the other half were diterpenes compounds $(46,50)$ (Table I). Copaiba essential oil showed 15 sesquiterpenes compounds (Table I). In this work, components with concentrations greater than $6.7 \%$ were considered as being the main representative components of the copaiba resin and essential oils and their partial solubility parameters and $\mathrm{HLB}_{0}$ were calculated.

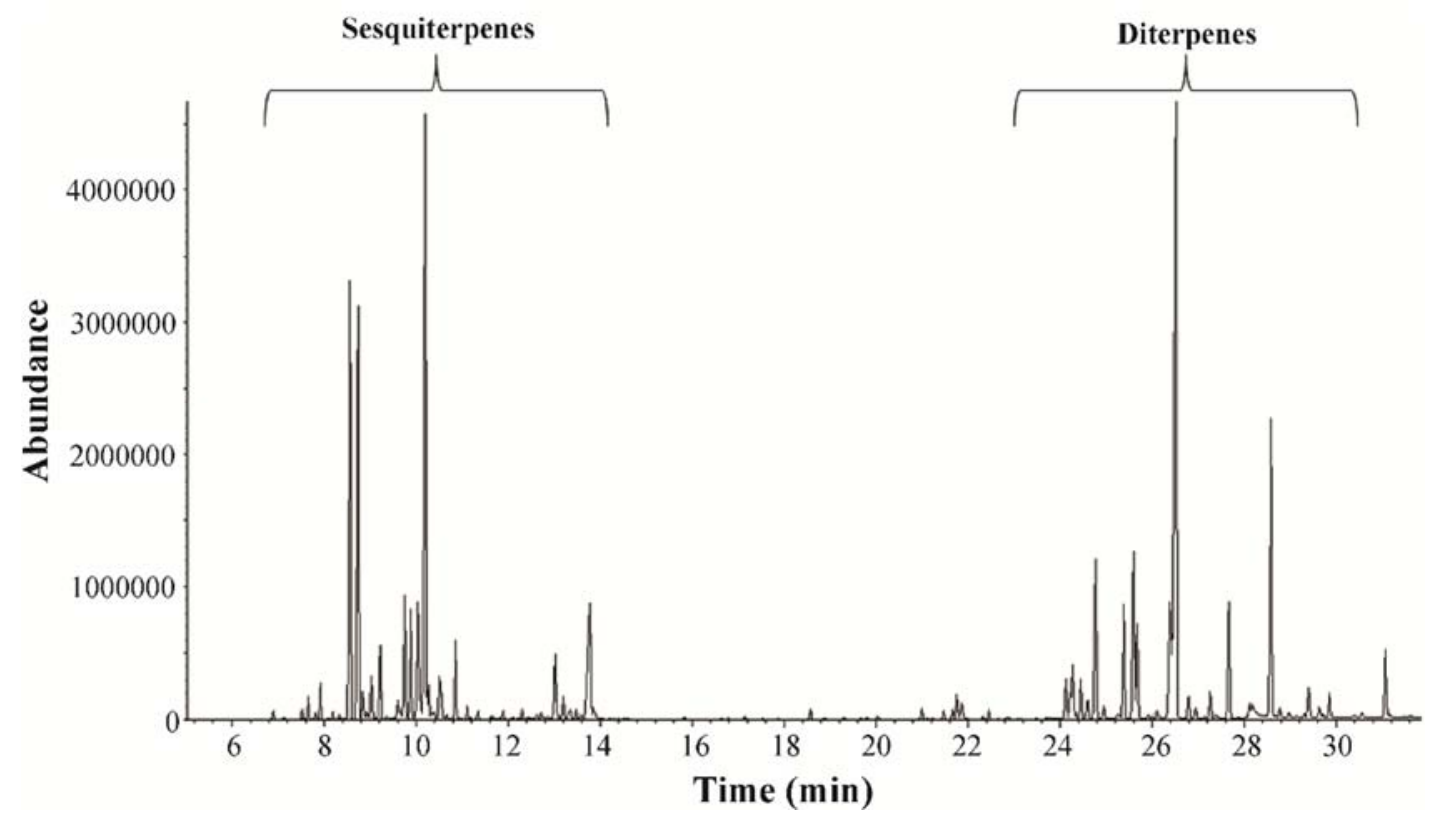

Figure 2 The copaiba resin oil chromatogram, with a typical sesquiterpenes and diterpenes compounds region. * Diterpenes compounds were obtained after methylation derivatization reaction. 
Table I Percentage of major compounds from Copaiba (Copaifera langsdorffii) resin and essential oils

\begin{tabular}{lccc}
\hline \multicolumn{1}{c}{ Chemical Compound* } & RT (min) & $\begin{array}{c}\text { Resin oil } \\
\text { (\%) }\end{array}$ & $\begin{array}{c}\text { Essential oil } \\
\text { (\%) }\end{array}$ \\
\hline B-Caryophyllene & 8.57 & 7.9 & 21.7 \\
$\alpha$-Bergamotene & 8.75 & 7.1 & 20.5 \\
$\beta$-Bisabolene & 10.21 & 12.3 & 23.6 \\
Copalic acid & 26.51 & 15.6 & - \\
Labd-8(20)-ene-15,18-dioic acid & 28.58 & 6.7 & - \\
\hline Compound concentration (<6.7\%) & & 43.3 & 32.0 \\
Not detected compounds (\%) & & 7.1 & 2.2 \\
Total identified (\%) & & 93.0 & 97.5 \\
\hline * compounds whin comp
\end{tabular}

* compounds which composition were above $6.7 \%$ of total components. RT (min): Retention time; (-) No detected.

\subsection{Calculation of solubility parameters of oil components and of lipophilic parts of surfactants}

Solubility parameters can be used to predict interactions between molecules that can be used in turn to predict their mutual miscibility and solubility (41). These parameters can be calculated from the contribution of cohesive energy of the different chemical groups composing the chemical structure of a component (43). Regarding miscibility and solubility of chemicals, a general principle based on like dissolves in like can be used to identify pairs of compounds that are miscible or appropriate solvents to dissolve a define molecule. This approach was used in formulation where several compounds need to be mixed $(40,41,45)$. Miscibility and/or solubility of components were optimized by matching solubility parameters of the components that needed to be incorporated in the formulation with those of the excipients. For instance, the approach was used to find surfactants showing the best theoretical miscibility of their lipophilic part with the selected oil formulating inverse emulsions and microemulsions with a given oil (45). Formulating O/W microemulsions including copaiba oil extracts as the dispersed phase, the aim of our work was to incorporate a high-volume fraction of copaiba oil using a minimum amount of surfactant. Oil extracts selected for this work were copaiba resin and essential oils. These oil extracts were expected to compose the dispersed phase of the microemulsion. A rational approach was adopted to select suitable surfactants assuming that optimizing miscibility's of lipophilic tails of surfactants with oil components based on a comparison of their solubility parameters and matching HLB of surfactants on the $\mathrm{HLB}_{0}$ of the oil would help formulating $\mathrm{O} / \mathrm{W}$ microemulsions with the desired composition (i.e., high- volume ratio of dispersed oil, oil to surfactant ratio above 1). At 
first, only dispersion forces between structural units were considered calculating solubility parameters from equations 1 and 2. To perform these calculations, the chemical structures of the lipophilic compounds were needed. The Figure 3 showed the chemical structure of surfactants and that of the main components found in the copaiba resin and essential oils. Lipophilic and hydrophilic parts of each molecule were highlighted and composition in chemical groups of the lipophilic part was taken to calculate the corresponding partial $\left(\delta_{p}, \delta_{d}\right.$, $\left.\delta_{h}\right)$ and total $\left(\delta_{t}\right)$ solubility parameters (Table II).

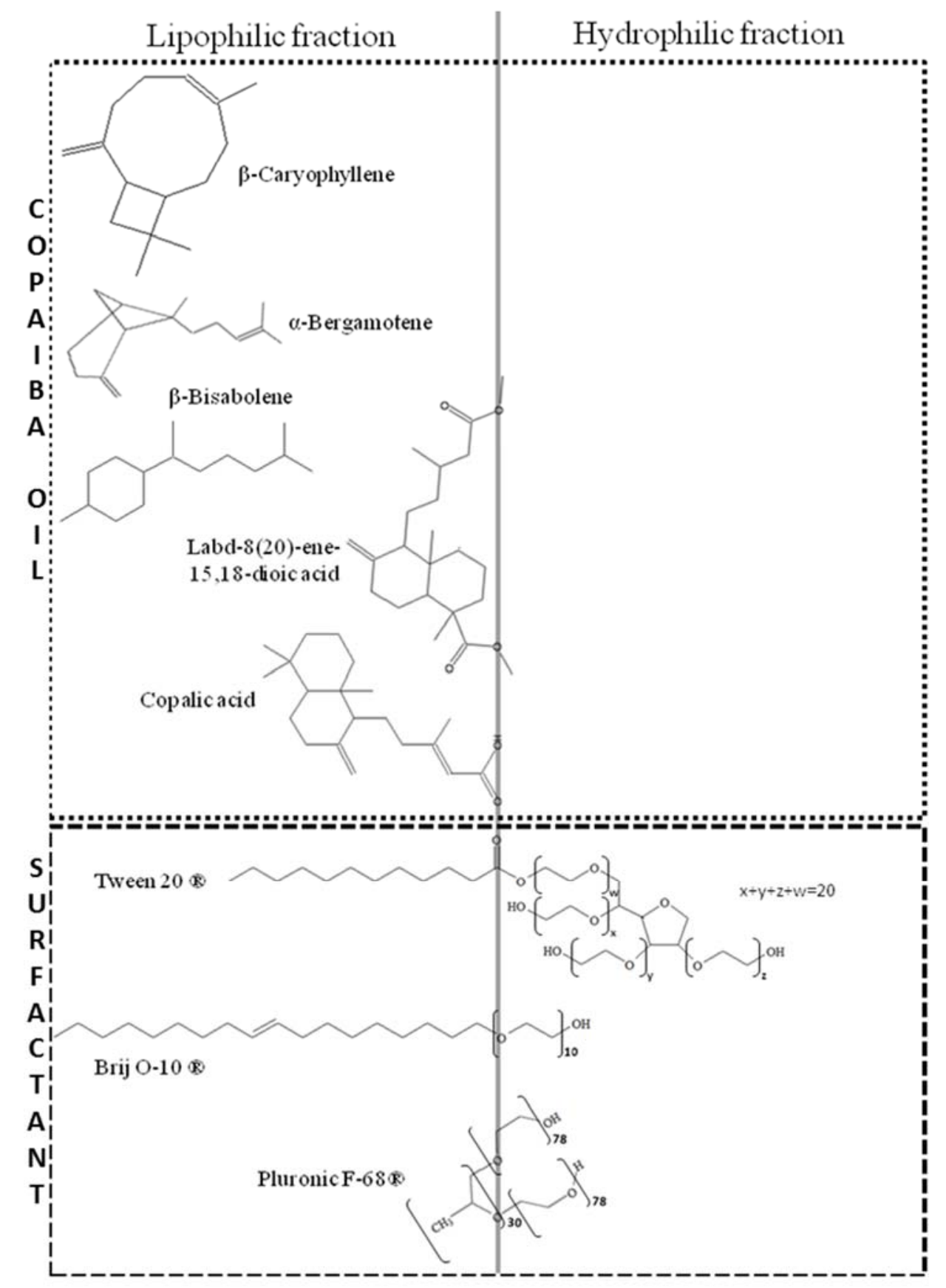

Figure 3 Chemical structure of the main compounds found in copaiba resin and essential oils showing their lipophilic and hydrophilic parts 
Table II Calculations of solubility parameters $\left(\mathrm{MJ}^{1 / 2} \mathrm{~m}^{-3 / 2}\right)$ and required Hydrophilic-Lipophilic Balance $\left(H L B_{0}\right)$ of the main compounds from copaiba resin and essential oils (top part of the table) and lipophilic chains of surfactants (bottom part of the table)

\begin{tabular}{|c|c|c|c|c|c|c|c|}
\hline $\begin{array}{l}\text { Compound } \\
\left(\mathrm{MJ}^{1 / 2} \mathrm{~m}^{-3 / 2}\right)\end{array}$ & Chemical contribution & $\delta_{d}$ & $\delta_{p}$ & $\delta_{h}$ & $\delta_{t}$ & $\mathrm{HLB}_{0}$ & HLB \\
\hline$\alpha$-Bergamotene & 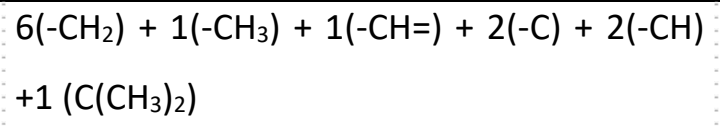 & 19.0 & 0.0 & 0.0 & 19.0 & 13.8 & \\
\hline$\beta$-Caryophyllene & $6\left(-\mathrm{CH}_{2}\right)+3\left(-\mathrm{CH}_{3}\right)+1(-\mathrm{CH}=)+3(-\mathrm{C})+2(-\mathrm{CH})$ & 20.1 & 0.0 & 0.0 & 20.1 & 14.2 & \\
\hline$\beta$-Bisabolene & $7\left(-\mathrm{CH}_{2}\right)+2\left(-\mathrm{CH}_{3}\right)+3(-\mathrm{CH}=)+1\left(-\mathrm{C}\left(\mathrm{CH}_{3}\right)_{2}\right)$ & 14.7 & 0.0 & 0.0 & 14.7 & 11.4 & \\
\hline Copalic acid & $\begin{array}{l}8\left(-\mathrm{CH}_{2}\right)+2\left(-\mathrm{CH}_{3}\right)+1(-\mathrm{CH}=)+3(-\mathrm{C})+2(-\mathrm{CH}) \\
+1 \mathrm{C}\left(\mathrm{CH}_{3}\right)_{2}+1(-\mathrm{COOH})\end{array}$ & 19.0 & 1.9 & 6.6 & 20.2 & 14.3 & \\
\hline $\begin{array}{l}\text { Labd-8(20)-ene- } \\
\text { 15,18-dioic acid }\end{array}$ & $9\left(-\mathrm{CH}_{2}\right)+3\left(-\mathrm{CH}_{3}\right)+2(-\mathrm{C})+3(-\mathrm{CH})+2(-\mathrm{COO}-)$ & 19.0 & 2.9 & 7.6 & 20.7 & 14.0 & \\
\hline Tween $^{\circ} 20$ & $10\left(-\mathrm{CH}_{2}\right)+1\left(-\mathrm{CH}_{3}\right)+1(-\mathrm{COO}-)$ & 16.5 & 2.3 & 5.7 & 17.6 & & 17.0 \\
\hline $\mathrm{Brij}^{-}-010$ & $15\left(-\mathrm{CH}_{2}\right)+1\left(-\mathrm{CH}_{3}\right)+2(-\mathrm{C}=)+1(-\mathrm{O}-)$ & 16.3 & 0.1 & 3.1 & 16.6 & & 12.9 \\
\hline Pluronic- F68 & $30\left(-\mathrm{CH}_{2}\right)+30\left(-\mathrm{CH}_{3}\right)+30(-\mathrm{CH})+30(-\mathrm{O}-)$ & 16.6 & 1.4 & 7.6 & 18.3 & & $29.0^{*}$ \\
\hline
\end{tabular}

* Result from the literature (55).

Total solubility parameters of the two copaiba oil extracts were calculated according to the percentage contribution in the composition of main compounds found in these complex mixtures. Copaiba essential and resin oils showed the calculated total solubility parameters of 17.8 and $18.7 \mathrm{MJ}^{1 / 2} \mathrm{~m}^{-3 / 2}$, respectively. These low values can be explained by the high contents of the extracts in sesquiterpenes and diterpenes hydrocarbons. The $\mathrm{HLB}_{0}$ of each main compound composing the copaiba oil extracts were calculated with equation 5. Considering the composition of the extract, the HLB oresin oil $_{\text {and }} \mathrm{HLB}_{\text {oessential oil }}$ were calculated from equation 6 giving values of 13.5 and 13.1 , respectively. The $H_{L} B_{\text {oresin oil }}$ was determined experimentally in a previous work (51). It is noteworthy that this experimental value was obtained at the expenses of a lot of work. There was a moderate difference $(\sim 10 \%)$ between the calculated and experimental values of the $H L B_{\text {oresin oil }}$ This difference can be explained from the known limitation of the theoretical approach used here that did not include contributions of all types of interactions that may occur between the molecules of different natures present in the copaiba resin oils.

Surfactants selected for this work can be used in composition of drug delivery systems designated for oral administration. Solubility parameters of the lipophilic part of each surfactant were calculated as well as the HLB of the molecules. Tween ${ }^{\circ} 20$, Brij $^{\circ} \mathrm{O} 10$ and Pluronic ${ }^{\oplus}$ F-68 showed the total solubility parameter calculated of $17.6,16.6$ and $18.3 \mathrm{MJ}^{1 / 2} \mathrm{~m}^{-}$ 
$3 / 2$, respectively. These surfactants showed the best chemical match with the oil components comparing each partial solubility parameters. Indeed, the chemical similarity determined between the lipophilic tail of the surfactants and the terpenes hydrocarbon group on the copaiba oil extracts was considered as the key factor for the formation of microemulsions optimizing the miscibility of the components. The HLB of the Tween 20 and Brij ${ }^{\circ} \mathrm{O} 10$ were calculated with equation 3 , being quite consistent with the results provided by the supplier. The HLB of the Pluronic ${ }^{\circ} \mathrm{F}-68$ was taken from the literature as the Griffin's equation applies to non-ionic surfactant which HLB bellow 20. To optimize the obtaining of the O/W microemulsion, surfactants were mixed at a composition where the HLB of the surfactant blend was identical to the $H L B_{0 o i l}$ calculated for copaiba resin $\left(H L B_{\text {oresin oil }}=13.5\right)$ and essential oil $\left(\mathrm{HLB}_{\text {oessential oil }}=13.1\right)$. The corresponding composition of the surfactants blends was calculated from equation 4 using the HLB of each surfactant and the HLB ooil $_{\text {value found for }}$ copaiba resin and essential oils. This approach was expected to provide stability of the disperse system at lower levels of surfactant(s) content while matching the HLB of the surfactant blend on that of the $\mathrm{HLB}_{\text {Oresin oil }}$ and $\mathrm{HLB}_{0 \text { essential oil, respectively. Tween }}{ }^{\circ} 20, \mathrm{Brij}^{\circ} \mathrm{O} 10$ and PluronicF- $68^{\circ}$ were used to produce microemulsion loaded with copaiba oil extracts. Thus, the selected

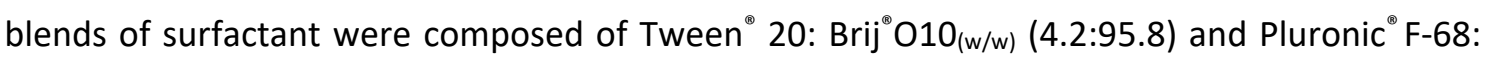

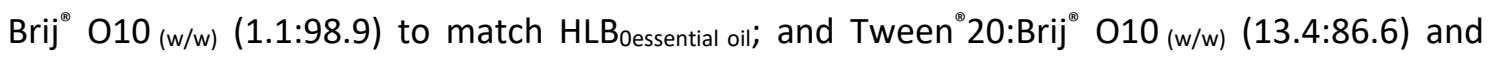

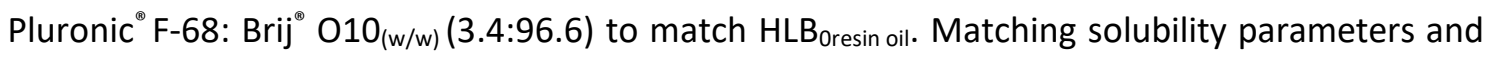
$\mathrm{HLB}_{0}$ were assumed to show the best compromise to stabilize droplets of copaiba oil extract in the internal phase of the O/W- microemulsions thanks to the optimization of the miscibility of the oil components with the lipophilic tails of the surfactants at the interface between the oil and the aqueous phase. In turn, it was expected that the optimization of the miscibility of these components would favorably contribute to enhance the stability of the interface between the oil droplets and the continuous aqueous phase allowing the dispersion of a highvolume fraction of oil in the microemulsion and minimizing the required amount of surfactant.

\subsection{Development of microemulsions}

A high-volume fraction of copaiba oil (> 15\%) and a low concentration of surfactant (oil to surfactant ratio $>1$ ) were determined as the goal of this work. Therefore, the copaiba oil extracts and Milli- $Q^{\circ}$ water were placed in test tubes at 25:75(w/w) and 15:85 $(\mathrm{w} / \mathrm{w})$ ratios corresponding as starting compositions. These mixtures were then titrated with surfactant blends which compositions were defined from the above calculations and with pure surfactants, sonicated and analyzed. Figure 4 shows regions in white where microemulsions 
were formed with copaiba essential and resin oils for different oil/surfactant ratios. Microemulsions could form with both types of copaiba oil extracts. However, the two types of oil extracts were not equivalent. Microemulsions were formed with only one blend of surfactant with the copaiba resin oil from the oil/water mixtures selected in this work and the amount of surfactant needed was much above the maximum set from our goal. In contrast, microemulsions which compositions fulfilled our goal could be obtained with the copaiba essential oil. Microemulsions were obtained with both types of surfactant blends while the lower amount of surfactant blend needed was $13.7 \%$, and the highest amount of dispersed copaiba essential oil was $19.6 \%$. Calculations performed to select surfactants optimizing the miscibility of their lipophilic moiety with main components found in the copaiba oil extracts were helpful to identify suitable surfactant blends to formulate microemulsions fulfilling the defined specifications with copaiba essential oil. The difference in the range of composition of the microemulsions that formed with the two types of oil extract can be explained by several factors. At first, the predictive calculations used to select surfactants are known to suffer from limitations as they do not consider all types of interactions that may occur between components. Second, the microemulsions were formulated with natural oil extracts which compositions were extremely complex. In the predictive calculation designated to optimize the miscibility of the oil components and the lipophilic moiety of the surfactant, only the main compounds were taken into account. All the compounds that are composing the oil, but which concentration were below $6.7 \%$ were ignored in the calculation. Obviously, this can create a major bias in the predictive calculation. The copaiba essential oil was the less complex mixture as essentially composed of sesquiterpenes at a high degree of purity. In comparison, the copaiba resin oil was much more complex in its composition. Thus, it can be assumed that the calculations were more predictive considering the formulation of microemulsions incorporating the copaiba essential oil. Last, some compounds of the oil may interfere in a positive manner in the formation of the interfacial film of surfactant. For instance, it can be postulated that compounds of the copaiba essential oil were playing the role of a co-surfactant allowing to reduce the amount of surfactant needed to form microemulsions with a quite large amount of dispersed oil. Despite limitations, the predictive approach used in this work helped the selection of suitable surfactants and their blends to formulate interesting microemulsions in terms of their composition. The obtaining of the microemulsions was straightforward without the need to explore the entire phase diagram and/or try different combination of surfactants. 


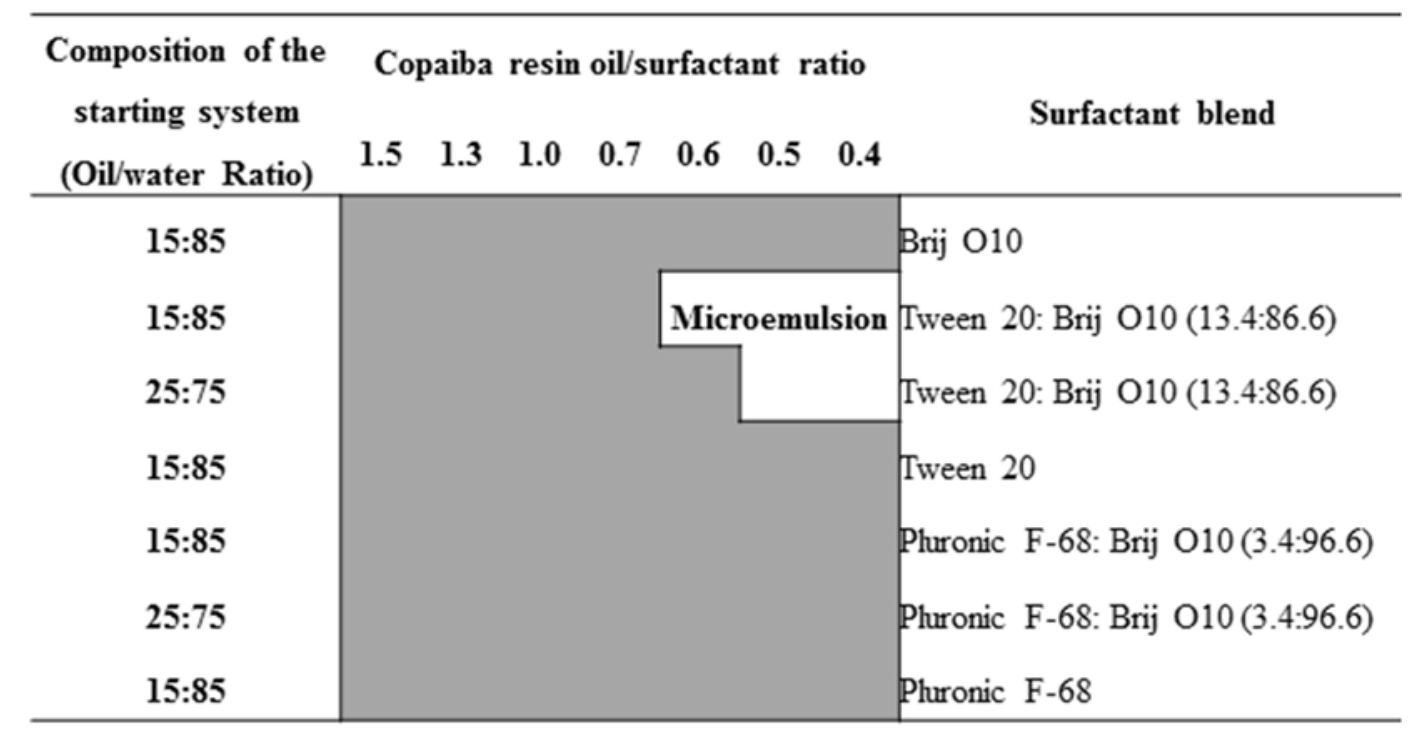

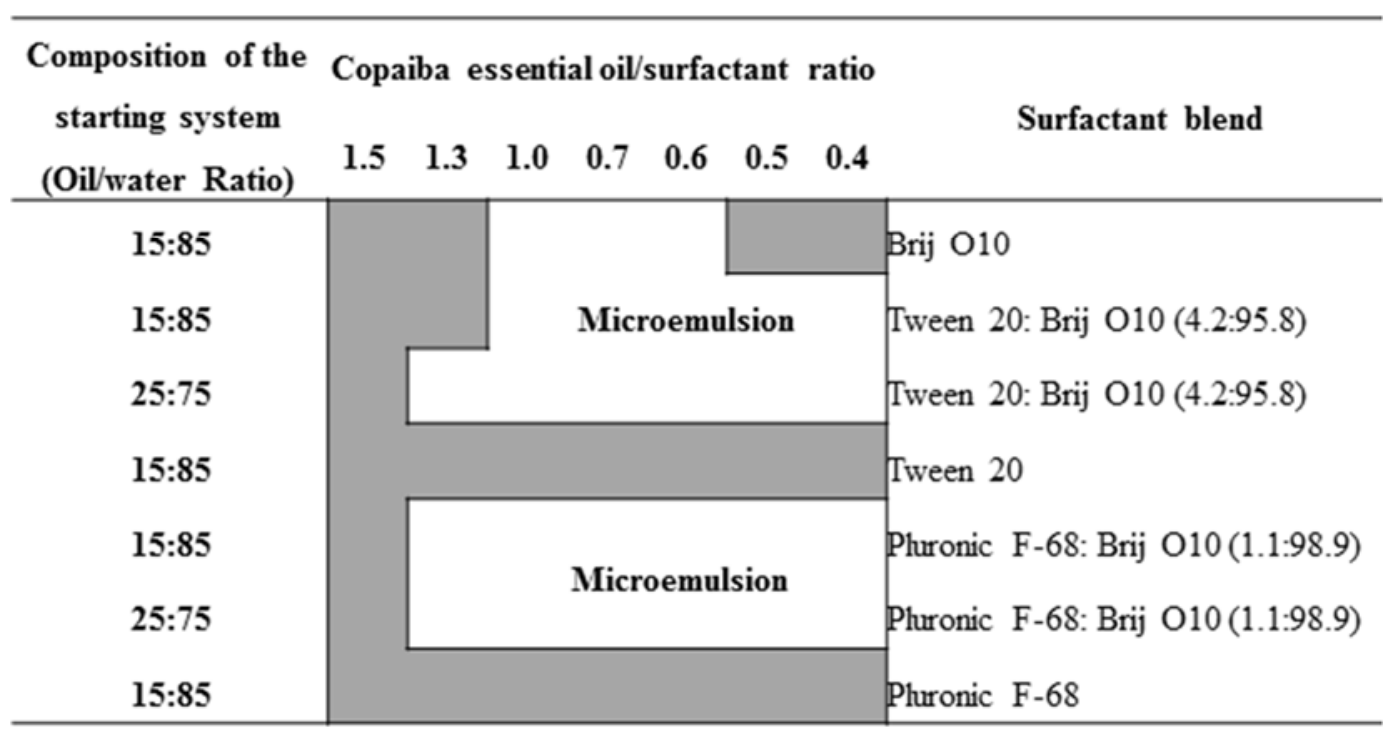

Figure 4 Formations of microemulsions with copaiba resin and essential oils with different blends of surfactants and starting at copaiba oil/water ratios of 15/85 or 25/75 respectively. White areas indicated the obtaining of transparent system corresponding to microemulsions.

The microemulsions formulated with copaiba essential oil and blends of either Pluronic ${ }^{\circ} \mathrm{F}-68$ : Brij $^{\circledR} \mathrm{O} 10$ (microemulsion A) and Tween $^{\circ}$ 20: Brij ${ }^{\circ} \mathrm{O} 10$ (microemulsion B) were further characterized as they reached the desired composition. Both microemulsions appeared homogeneous and showed the characteristic Tyndall effect of colloidal dispersions (Figure 5). Consistently, the transmittance of light measured at $25^{\circ} \mathrm{C}$ was 72 and $55 \%$ for the microemulsion $A$ and $B$, respectively. They also appeared homogenous while observed through a light microscope with the phase contrast mode. They were isotropic when observed under polarized light microscopy consistently with usual optical properties described for microemulsions (15). 


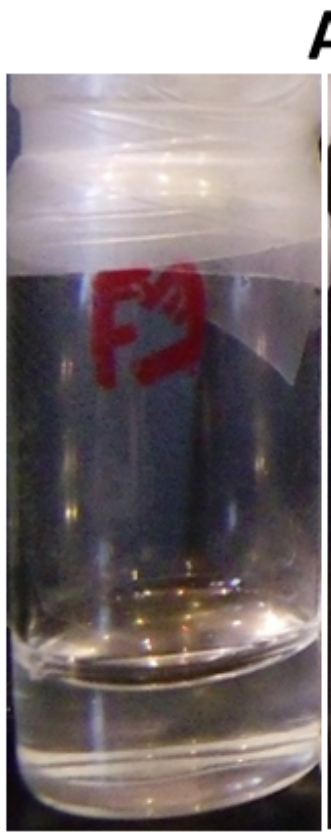

0
A

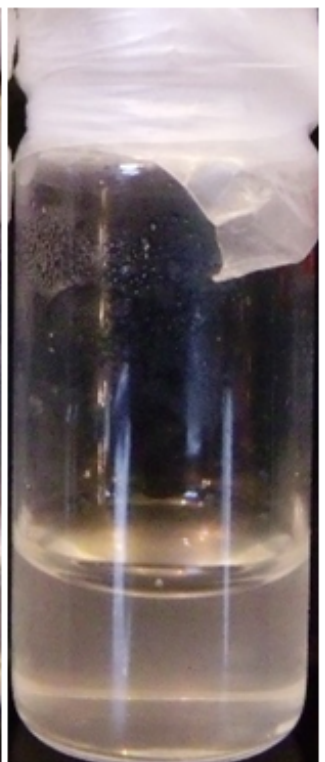

30

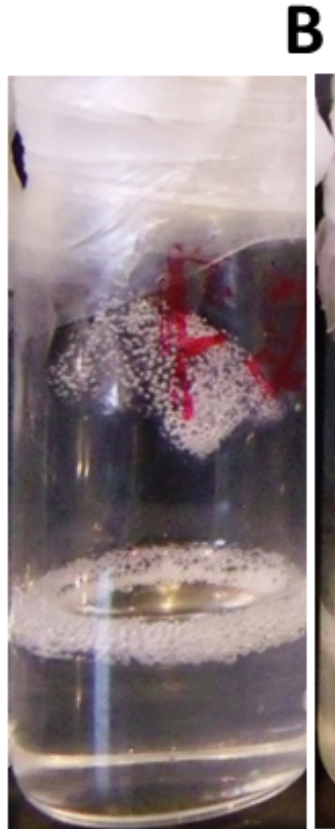

0
B

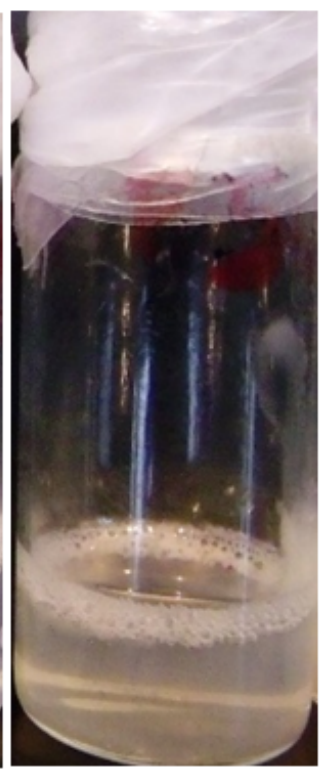

30

Time after preparation (days)

Figure 5 Macroscopic aspects of the microemulsion A composed of copaiba essential oil $19.6 \%$, Pluronic ${ }^{\circ}$ F-68: Brij ${ }^{\circ}$ O10 mixtures at 1.1:98.9 $(\mathrm{w} / \mathrm{w})$ ratio $13.7 \%$, water $66.7 \%$, and microemulsion B composed of copaiba essential oil $19.6 \%$; Tween ${ }^{\circledR} 20$ : Brij ${ }^{\circ} 010$ mixtures at 4.2:95.8 (w/w) ratio $13.7 \%$, water $66.7 \%$, right after preparation ( 0 day) and after 30 days storage at $37^{\circ} \mathrm{C}$.

The results of droplet size measurement, $\mathrm{Pdl}$ and $\mathrm{pH}$ of the formulations were summarized in the Table III. Microemulsion A showed lower mean diameter and PdI than the formulation B. The size distribution with a Pdl of less than 0.25 indicated a narrow size distribution of the microemulsion and consequently a homogenous monomodal distribution. $\mathrm{By} \mathrm{pH}$ measurement, it was possible to verify the presence of an aqueous external phase, since the microemulsion $\mathrm{pH}$ value obtained was very close to that of the Milli-Q water. The $\mathrm{pH}$ of the continuous phase of microemulsion can significantly influence the stability of colloidal systems because of the ionization and surface charges of microemulsion droplets. Zeta potentials of the microemulsions $A$ and $B$ were $1.43 \pm 0.30$ and $-1.76 \pm 0.12$, respectively. These values were close to the neutrality suggested that the microemulsions were stabilized through a steric effect thanks to the macromolecular characteristics of the polar head group of the surfactants. As indicated from the measurement of the size of the microemulsion droplets after one month of storage at $37^{\circ} \mathrm{C}$ (Table III) and from the visual aspects of the microemulsions (Figure 5), they were stable over time. 
Table III The droplet size, $\mathrm{Pdl}$ and $\mathrm{pH}$ of microemulsions formulated with copaiba essential oil and a blend of Pluronic ${ }^{\circ}$ F-68: Brij 010 at 1.1:98.9 (w/w) ratio (microemulsion A) and with a blend of Tween ${ }^{\circ}$ 20: Brij 010 at 4.2:95.8 (w/w) ratio (microemulsion B) immediately after preparation ( 0 day) and 30 days after storage at $37^{\circ} \mathrm{C}$. The oil content and surfactant content of both microemulsions were 19.6 and $13.7 \%$, respectively.

\begin{tabular}{|c|c|c|c|c|c|c|}
\hline \multirow{2}{*}{ Microemulsion } & \multirow{2}{*}{ General characteristics } & \multicolumn{3}{|l|}{0 day } & \multicolumn{2}{|l|}{30 days } \\
\hline & & Size (nm) & Pdl & $\mathrm{pH}$ & Size $(\mathrm{nm})$ & Pdl \\
\hline A & $\begin{array}{l}\text { Translucent / tyndall effect, } \\
\text { homogeneous and isotropic }\end{array}$ & $42 \pm 0.5$ & $0.13 \pm 0.01$ & $6.5 \pm 0.1$ & $45 \pm 0.7$ & $0.14 \pm 0.01$ \\
\hline B & $\begin{array}{l}\text { Translucent / tyndall effect, } \\
\text { homogeneous and isotropic }\end{array}$ & $95 \pm 10$ & $0.31 \pm 0.03$ & $6.0 \pm 0.2$ & $128 \pm 24$ & $0.29 \pm 0.06$ \\
\hline
\end{tabular}

Rheology behavior is a fundamental approach to provide useful information about the microemulsion structure and stability (52). Figure 6 shows the rheology behavior of the copaiba essential oil containing microemulsions $A$ and $B$. Both formulations (A) and $(B)$ showed a shear-thinning behavior. Between 0.1 and $4 \mathrm{~s}^{-1}$, both formulations exhibited similar viscosity values. Above $10 \mathrm{~s}^{-1}$, formulations (A) had lower viscosities values than formulation (B). Thus, the relatively lower viscosity values of $A$ may indicate that this microemulsion was composed of larger, less aggregated and spherical droplets than in microemulsion $B$, which is confirmed by the results obtained by size measurement and polarized light microscopy $(14,53)$.

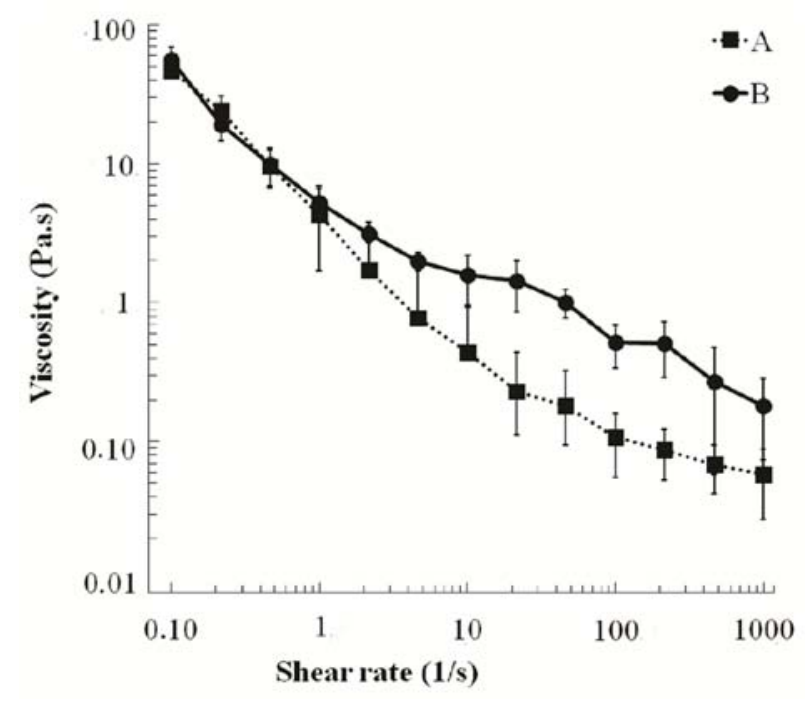

Figure 6 Flow curves of microemulsions formulated with copaiba essential oil and with a blend of Pluronic ${ }^{\circ} \mathrm{F}-68$ : Brij $^{\circ} \mathrm{O} 10$ at 1.1:98.9 ratio (microemulsion A) and with a blend of Tween ${ }^{\circ} 20$ : Brij $^{\circ} \mathrm{O} 10$ at 4.2:95.8 ratio (microemulsion B). The oil content and surfactant content of both microemulsions were 19.6 and $13.7 \%$, respectively. 
Figure 7 showed the comparison of gas chromatograms obtained after analysis of the copaiba essential oil and of the microemulsion.
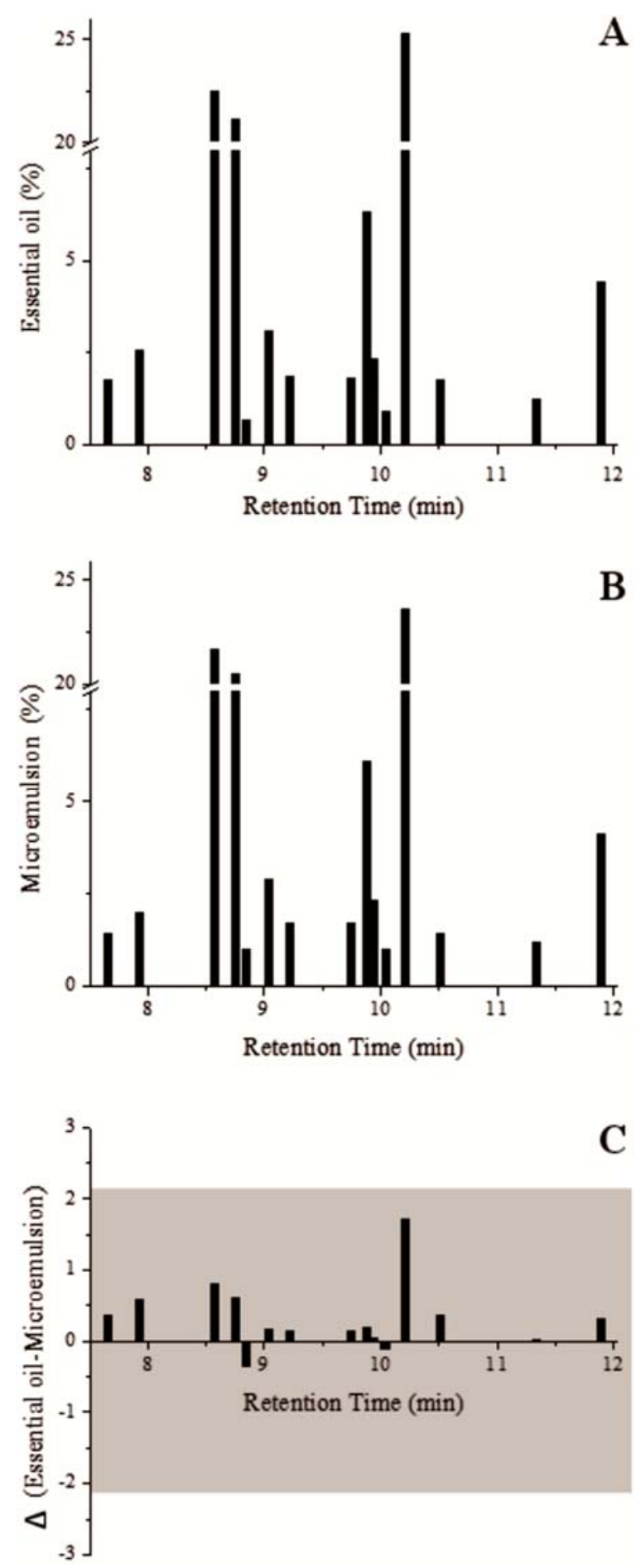

Figure 7 Comparison of chromatograms obtained by gas chromatography analysis of copaiba essential oil (A) and microemulsion prepared with copaiba essential oil (B) by GC-FID analysis. $C$ is the percentage difference between $A$ and $B$. The gray color represents the precision of the method to determination of copaiba oil compounds. 
The data indicated that there was no significant difference in the composition between the copaiba essential oil extracted from the microemulsion and that of the copaiba essential oil itself $(p>0.05)$. Precision of the method to quantify components found in the copaiba oil extract was $2.4 \%$ and variation founds between the analysis of the oil extracted from the microemulsion and that of the essential oil felt within this range (Figure $7 \mathrm{C}$ ). From the quantitative analysis of the chromatograms, it could be determined that the copaiba essential oil-loaded microemulsion $A$ that contained the highest volume fraction for the lower concentration in surfactant (13.7\% of Pluronic ${ }^{\circ} \mathrm{F}-68$ : Brij $^{\circ} \mathrm{O} 10$ blend) included a concentration of $3.8 \mathrm{mg} \cdot \mathrm{mL}^{-1}$ of $\beta$-caryophyllene. This sesquiterpenes has been showed to produce synergistic effect with other anticancer drugs in anticancer therapies thanks to its property to enhance the permeability of cell membranes allowing a higher accumulation of anticancer drugs within cells hence anticancer activity of the drug (54). To take advantage of this synergistic effect, it could be interesting to incorporate an anticancer agent that is known to take benefit of this effect within this microemulsion. It is noteworthy that microemulsions formulated in the present work were obtained with rather low content of surfactant $(<15 \%)$ and oil/surfactants ratio much above 1 . The performance of these microemulsions was much above those of the literature considering their oil content compared with their surfactant content (Figure 1, black bar on the right). These microemulsions were formulated with copaiba essential oil that is a complex mixture of compounds and using a rational approach for the selection of the surfactants based on a chemical compatibility with the main components of the oil. This work shows that concepts based on HLB proposed by Beerbower and Hill (42) and on solubility parameters proposed by Hansen (43) are valuable helping formulation of oil in water microemulsions with oils of complex composition. The application of these concepts has considerably limited the amount of experimental work needed to formulate the desired microemulsions.

\section{CONCLUSION}

In this work, a predictive approach was used to select type and composition of surfactants to formulate $\mathrm{O} / \mathrm{W}$ microemulsions incorporating natural oil extracts as the dispersed phase. The selection was based on the prediction of the chemical compatibility of the lipophilic part of the surfactant molecule with oil components comparing their Hansen solubility parameters. Then, the composition of the surfactant blend was predicted from the calculation of the required HLB of the copaiba oil extracts. Results of these calculations suggested two blends of surfactants. These blends of surfactants were suitable formulating microemulsions with both 
types of copaiba oil extracts (i.e., resin and essential oil) considered in the work. The more interesting microemulsions incorporating the highest amount of oil (19.6\%) and the lower amount of surfactant $(13.7 \%)$ were obtained with the less complex oil extract, i.e., the essential oil that was composed of highly purified sesquiterpenes. Following the predictive approach based on the optimization of the chemical compatibility of compounds that are mixed together in the formulation, microemulsions with much higher content in dispersed oil and low requirement of surfactant compared to those of the literature could be formulated at the expense of a low experimental workload. Due to their low content in surfactant and large amount of dispersed oil, microemulsions formulated with copaiba essential oil could be proposed as delivery system for the oral administration of this oil as it is a drug by itself or after incorporation of an anticancer drug with which the copaiba oil is known to develop a synergetic activity.

\section{ACKNOWLEDGMENTS}

This work was financially supported by the "coordenação de aperfeiçoamento de pessoal de nível superior" CAPES COFECUB 721/11. The authors wish to thank Dr Alexandre Maciuk for his help in the dosage of Copaiba Oil.

\section{REFERENCES}

1. Muzaffar F, Singh UK, Chauhan L. Review on microemulsion as futuristic drug delivery. Int J Pharm Pharm Sci. 2013;5:39-53.

2. Lawrence MJ, Rees GD. Microemulsion-based media as novel drug delivery systems. Adv Drug Deliv Rev. 2012;64:175-193.

3. Araya $\mathrm{H}$, Tomita $\mathrm{M}$, Hayashi $\mathrm{M}$. The novel formulation design of $\mathrm{O} / \mathrm{W}$ microemulsion for improving the gastrointestinal absorption of poorly water soluble compounds. Int J Pharm. 2005;305(1-2):61-74.

4. Gibaud S, Attivi D. Microemulsions for oral administration and their therapeutic applications. Expert Opin Drug Deliv. 2012;9(8):937-951.

5. Danielsson I, Lindman B. The definition of microemulsion. Colloids Surf. 1981;3(4):391392.

6. McClements DJ. Nanoemulsions versus microemulsions: Terminology, differences, and similarities. Soft Matter. 2012;8:1719-1729

7. Hoar TP, Schulman JH. Transparent water-in-oil dispersions: The oleopathic hydromicelle. Nature. 1943;152:102-104.

8. Souza AB, Martins CH, Souza MG, Furtado NA, Heleno VC, de Sousa JP, Rocha EM, Bastos JK, Cunha WR, Veneziani RC, Ambrosio SR. Antimicrobial activity of terpenoids from Copaifera langsdorffii Desf. against cariogenic bacteria. Phytother Res. 2011;25(2):215-220. 
9. Comelli Júnior E, Skinovski J, Sigwalt MF, Branco AB, Luz SR, Baulé CP. Rupture point analysis of intestinal anastomotic healing in rats under the action of pure Copaíba (Copaifera langsdorfii) oil. Acta Cir Bras. 2010;25:362-367.

10. Gomes N M, Rezende C M, Fontes SP, Hovell AM, Landgraf RG, Matheus ME, Pinto A C, Fernandes PD. Antineoplasic activity of Copaifera multijuga oil and fractions against ascitic and solid Ehrlich tumor. J Ethnopharmacol. 2008;119(1):179-184.

11. Attaphong C, Do L, Sabatini DA. Vegetable oil-based microemulsions using carboxylatebased extended surfactants and their potential as an alternative renewable biofuel. Fuel. 2012;94(1):606-613.

12. Lee MJ, Lee MH, Shim CK. Inverse targeting of drugs to reticuloendothelial system-rich organs by lipid microemulsion emulsified with poloxamer-338. Inter J Pharm. 1995;113(2):175-187.

13. Zhang $H$, Shen $Y$, Bao $Y$, He $Y$, Feng $F$, Zheng $X$. Characterization and synergistic antimicrobial activities of food-grade dilution-stable microemulsions against Bacillus subtilis. Food Res Int. 2008;41(5):495-499.

14. Djordjevic L, Primorac M, Stupar M, Krajisnik D. Characterization of caprylocaproyl macrogolglycerides based microemulsion drug delivery vehicles for an amphiphilic drug. Int J Pharm. 2004;271(1-2):11-19.

15. Boonme P, Krauel K, Graf A, Rades T, Junyaprasert VB. Characterization of microemulsion structures in the pseudoternary phase diagram of isopropyl palmitate/water/Brij 97:1-butanol. AAPS PharmSciTech. 2006;7(2):99-104.

16. Ghosh V, Saranya S, Mukherjee A, Chandrasekaran N. Antibacterial microemulsion prevents sepsis and triggers healing of wound in wistar rats. Colloids Surf B Biointerfaces. 2013;105:152-157.

17. Teixeira PC, Leite GM, Domingues RJ, Silva J, Gibbs PA, Ferreira JP. Antimicrobial effects of a microemulsion and a nanoemulsion on enteric and other pathogens and biofilms. Int J Food Microbiol. 2007;118(1):15-19.

18. Hamed SF, Sadek Z, Edris A. Antioxidant and antimicrobial activities of clove bud essential oil and eugenol nanoparticles in alcohol-free microemulsion. J Oleo Sci. 2012;61(11):641-648.

19. Surjyanarayan M, Snigdha SM, Naazneen S. Design and development of Saquinavir microemulsion for the oral bioavailability enhancement. Int J PharmTech Res. 2009;1:1442-1448.

20. Borhade $\mathrm{V}, \mathrm{Nair} H$, Hegde D. Design and evaluation of self-microemulsifying drug delivery system (SMEDDS) of tacrolimus. AAPS PharmSciTech. 2008;9(1):13-21.

21. Hu L, Wu H, Niu F, Yan C, Yang X, Jia Y. Design of fenofibrate microemulsion for improved bioavailability. Int J Pharm. 2011;420(2):251-255.

22. Dantas TNC, Silva HSRC, Neto AAD, Marcucci MC, Maciel MAM. Development of a new propolis microemulsion system for topical applications. Rev bras farmacogn. 2010;20(3):368-375.

23. Yi C, Zhong H, Tong S, Cao X, Firempong CK, Liu H, Fu M, Yang Y, Feng Y, Zhang H, Xu X, $\mathrm{Yu}$ J. Enhanced oral bioavailability of a sterol-loaded microemulsion formulation of Flammulina velutipes, a potential antitumor drug. Int J Nanomedicine. 2012;7:50675078.

24. Spernath A, Yaghmur A, Aserin A, Hoffman RE, Garti N. Food-grade microemulsions based on nonionic emulsifiers: media to enhance lycopene solubilization. J Agric Food Chem. 2002;50(23):6917-6922.

25. Rao J, McClements DJ. Formation of flavor oil microemulsions, nanoemulsions and emulsions: influence of composition and preparation method. J Agric Food Chem. 2011;59(9):5026-5035. 
26. Jha SK, Karki R, Venkatesh DP, Geethalakshami A. Formulation development and characterization of microemulsion drug delivery systems containing antiulcer drug. Int J Drug Dev Res. 2011;3(4):336-343.

27. Lee H, Soo PL, Liu J, Butler M, Allen C. Polymeric micelles for formulation of anti-cancer drugs. In: Amiji MM, editor. Nanotechnology for Cancer Therapy: CRC Press; 2006. p. 329.

28. Tian $Q$, Ren F, Xu Z, Xie Y, Zhang S. Preparation of high solubilizable microemulsion of naproxen and its solubilization mechanism. Int J Pharm. 2012;426(1-2):202-210.

29. Biresh KS, Shiv SH. Microemulsion drug delivery system for oral bioavailability enhancement of glipizide. J Adv Pharm Technol Res. 2011;1(4):195-200.

30. Mrestani Y, Behbood L, Hartl A, Neubert RH. Microemulsion and mixed micelle for oral administration as new drug formulations for highly hydrophilic drugs. Eur J Pharm Biopharm. 2010;74(2):219-222.

31. Solanki SS, Sarkar B, Dhanwani RK. Microemulsion drug delivery system: for bioavailability enhancement of ampelopsin. ISRN Pharm. 2012;2012:1-4.

32. Pestana KC, Formariz TP, Franzini CM, Sarmento VH, Chiavacci LA, Scarpa MV, Egito ES, Oliveira AG. Oil-in-water lecithin-based microemulsions as a potential delivery system for amphotericin B. Colloids Surf B Biointerfaces. 2008;66(2):253-259.

33. Gao Z-G, Choi H-G, Shin H-J, Park K-M, Lim S-J, Hwang K-J, Kim C-K. Physicochemical characterization and evaluation of a microemulsion system for oral delivery of cyclosporin A. Int J Pharm. 1998;61(1):75-86.

34. Acharya A, Sanyal SK, Moulik SP. Physicochemical investigations on microemulsification of eucalyptol and water in presence of polyoxyethylene (4) lauryl ether (Brij-30) and ethanol. Int J Pharm. 2001;229(1-2):213-226.

35. Agatonovic-Kustrin S, Glass BD, Wisch MH, Alany RG. Prediction of a stable microemulsion formulation for the oral delivery of a combination of antitubercular drugs using ANN methodology. Pharm Res. 2003;20(11):1760-1765.

36. Zeng Z, Zhou G, Wang X, Huang EZ, Zhan X, Liu J, Wang S, Wang A, Li H, Pei X, Xie T. Preparation, characterization and relative bioavailability of oral elemene $\mathrm{o} / \mathrm{w}$ microemulsion. Int J Nanomedicine. 2010;5:567-572.

37. Sapra B, Bhandari S, Sood J, Jindal M, Tiwary A, Tiwary A. A critical appraisal of microemulsions for drug delivery: part I. Ther Deliv. 2013;4(12):1547-1564.

38. He CX, Gao J-Q, Gao JQ. Microemulsions as drug delivery systems to improve the solubility and the bioavailability of poorly water-soluble drugs. Expert Opin Drug Deliv. 2010;7(4):445-460.

39. Barton AFM. Handbook of solubility parameters and other cohesive parameters. New York; 1983.

40. Hancock BC, York P, Rowe RC. The use of solubility parameters in pharmaceutical dosage form design. Int J Pharm. 1997;148(1):1-21.

41. Lim SM, Pang ZW, Tan HY, Shaikh M, Adinarayana G, Garg S. Enhancement of docetaxel solubility using binary and ternary solid dispersion systems. Drug Dev Ind Pharm. 2015;41(11):1847-1855.

42. Beerbower A, Hill MW. Detergents and emulsifiers: Allured Publishing Co; 1971.

43. Hansen $\mathrm{CM}$. The three dimensional solubility parameter - key to paint component affinities ii. - dyes, emulsifiers, mutual solubility and compatibility, and pigments. J Paint Technol. 1967;39(511):505-510.

44. Hildebrand JH, Prausnitz JM, Scott RL. Regular and related solutions. New York: Van Nostrand Reinhold; 1970.

45. Holtzscherer C, Candau F. Application of the cohesive energy ratio concept (CER) to the formation of polymerizable microemulsions. Colloids Surf. 1988;29(4):411-423. 
46. Xavier-Junior FH, Maciuk A, Morais ARV, Alencar EN, Rehder VLG, Egito EST, Vauthier C. Copaiba oil analysis by gas-chromatography coupled to mass spectroscopy and flame ionization detection. Submitted for publication.

47. van Krevelen DW, Hoftyzer PJ. Properties of polymers: Their estimation and correlation with chemical structure. Amsterdam: Elsevier; 1976.

48. Griffin WC. Classification of Surface-Active Agents by 'HLB'. J Soc Cosmet Chem. 1949;1(5):311-326.

49. Griffin WC. Calculation of HLB values of non-ionic surfactants. J Soc Cosmet Chem. 1954;5(4):249-256.

50. Alencar EN, Xavier-Júnior FH, Morais ARV, Dantas TRF, Dantas-Santos N, Verissimo LM, Rehder VLG, Chaves GM, Oliveira AG, Egito EST. Chemical characterization and antimicrobial activity evaluation of natural oil nanostructured emulsions. J Nanosci Nanotechnol. 2015;15(1):880-888.

51. Xavier-Júnior FH, Silva KGH, Farias IEG, Morais ARV, Alencar EN, Araújo IB, Oliveira AG, Egito EST. Prospective study for the development of emulsion systems containing natural oil products. J Drug Del Sci Tech. 2012;22(4):367-372.

52. Formariz TP, Chiavacci LA, Scarpa MV, Silva-Júnior AA, Egito EST, Terrugi CHB, Franzini $\mathrm{CM}$, Sarmento VHV, Oliveira AG. Structure and viscoelastic behavior of pharmaceutical biocompatible anionic microemulsions containing the antitumoral drug compound doxorubicin. Colloids Surf B Biointerfaces. 2010;77(1):47-53.

53. Acharya DP, Hartley PG. Progress in microemulsion characterization. Curr Opin Colloid Interface Sci. 2012;17(5):274-280.

54. Legault J, Pichette A. Potentiating effect of beta-caryophyllene on anticancer activity of alpha-humulene, isocaryophyllene and paclitaxel. J Pharm Pharmacol. 2007;59(12):1643-1647.

55. Prakash AS. Selecting surfactants for the maximum inhibition of the activity of the multidrug resistance efflux pump transporter, P-glycoprotein: conceptual development. J Excip Food Chem. 2010;1(3):51-59. 